\title{
The Benzopyrone Biochanin-A as a reversible, competitive, and selective monoamine oxidase $B$ inhibitor
}

\author{
Najla O. Zarmouh, Suresh K. Eyunni and Karam F. A. Soliman*
}

\begin{abstract}
Background: Monoamine oxidase-B (MAO-B) inhibitors are widely used in the treatment of Parkinson's disease. They increase vital monoamine neurotransmitters in the brain. However, there is a need for safer natural reversible MAO inhibitors with MAO-B selectivity. Our previous studies showed that Psoralea corylifolia seeds (PCS) extract contains compounds that inhibit monoamine oxidase-B.

Methods: In this study, six of PCS constituents sharing a benzopyrone structure were investigated. The compounds Biochanin-A (BIO-A), isopsoralen, 6-prenylnaringenin, neobavaisoflavone, psoralen, and psoralidin, were tested for their ability to inhibit recombinant human MAO-A and B (hMAO-A and hMAO-B) isozymes. The ability of these compounds to inhibit MAO-A and MAO-B were compared to that of PCS ethanolic extract (PCSEE) using spectrophotometric assays and confirmed by luminescence assays. The highly potent and selective MAO-B inhibitor, $\mathrm{BIO}-\mathrm{A}$, was further investigated for both isozymes reversibility and enzyme kinetics. Molecular docking studies were used to predict the bioactive conformation and molecular interactions of BIO-A with both isozymes.

Results: The data obtained indicate that benzopyrones inhibited $h M A O-A$ and $h M A O-B$ with different degrees as confirmed with the luminescence assay. BIO-A inhibited hMAO-B with high potency and selectivity in the present study $\left(\mathrm{IC}_{50}=0.003 \mu \mathrm{g} / \mathrm{mL}\right)$ and showing 38-fold more selectivity than PCSEE (hMAO-B IC $50=3.03 \mu \mathrm{g} / \mathrm{mL}$, 17-fold selectivity) without affecting hydrogen peroxide. Furthermore, BIO-A reversibly and competitively inhibited both hMAOs with significantly lower inhibitory constant $\left(\mathrm{K}_{\mathrm{i}}\right)$ in hMAO-B (3.8 nM) than hMAO-A (99.3 nM). Our docking studies indicated that the $\mathrm{H}$-bonds and hydrophobic interactions at the human MAO-A and MAO-B active sites contributed to the reversibility and selectivity of BIO-A.
\end{abstract}

Conclusions: The data obtained indicate that BIO-A is a potent, reversible and selective MAO-B inhibitor and may be recommended for further investigation in its possible use in the therapeutic management of Parkinson's and Alzheimer's diseases.

Keywords: Human monoamine oxidase-A, Human monoamine oxidase-B, Benzopyrone, Psoralea corylifolia ethanolic extract, Flavonoids, Coumarins, Biochanin-A, Reversible competitive inhibition, Docking studies

* Correspondence: karam.soliman@famu.edu

College of Pharmacy and Pharmaceutical Sciences, Florida A\&M University,

Tallahassee, FL 32307, USA 


\section{Background}

Human monoamine oxidases $\mathrm{A}$ and $\mathrm{B}$ isozymes (MAO-A and $\mathrm{MAO}-\mathrm{B})$ regulate neurotransmitters such as dopamine (DA), norepinephrine (NE), and serotonin (5-HT) [1]. These metabolizing isozymes belong to the family of flavincontaining amine oxidoreductases and are in the mitochondrial membranes of brain neurons and glia, in addition to other peripheral cells. In neurological disorders with depleting neurotransmitters, selective and non-selective MAO inhibitors (MAOIs) are used. The specific MAO-BIs are well-established therapeutics for Parkinson's disease (PD), and currently paving new avenues for Alzheimer disease (AD) patients [2]. Meanwhile, the non-selective and selective inhibitors of MAO-A (MAO-AIs) are used primarily for patients who have not responded to other antidepressants therapy [1]. Some of these therapeutic agents such as moclobemide and pirlindole are currently in use.

MAOIs can exert multiple pharmacological actions by reducing the enzymatically formed hydrogen peroxide $\left(\mathrm{H}_{2} \mathrm{O}_{2}\right)$ and aldehydes cytotoxic byproducts [3], antiapoptotic effects [4] and increasing DA which indirectly attenuates nitric oxide [5]. These pharmacological properties of MAOIs can provide neuroprotection against oxidative stress and cell death [1], making them effective against neurodegeneration. However, the inevitable rare incidences of the MAOIs side-effects reaction are causing concerns. Nonetheless, the newly emerged class of reversible inhibitors of MAO-A (RIMA), clinically showed almost no cheese effect or need for diet restrictions [6]. Thus, it is important to find reversible inhibitors for effective and safer use emphasized investigations for a new level for MAOs inhibition and MAO inhibitors.

It is of interest to note that some synthesized coumarin derivatives have potent MAO inhibitions [7, 8]. In addition, natural coumarins and flavonoids were found to be beneficial for neurological disorders $[9,10]$, with potent effects on the synthesis of catecholamines and oxidative stress [11, 12]. Such shared general benzopyrone structure between flavonoids and coumarins emphasize a high potential to inhibit MAO-B. Notably, Psoralea corylifolia L. seeds (PCS) (Plant common name: bakuchi, family: Leguminosae) [13] contain a variety of benzopyrone structures as in coumarins and flavonoids derivatives with chromone core structures [14]. We previously reported that PCS ranked one of the most potent plant extracts to inhibit recombinant human $(h)$ MAO-B activity among 905 screened extracts [15]. Further, we have shown the significant selectivity of these compounds to MAO-B as compared to MAO-A [16]. Furthermore, the unique constituent of PCS., i.e., bavachinin, showed a reversible $h \mathrm{MAO}$ inhibition with an $h \mathrm{MAO}-\mathrm{B}$ relative selectivity $\left(\mathrm{RS}_{\mathrm{B}}\right)$ [17]. In a previously reported phytochemical screening, the plant seeds were suggested to be a good source for phytomedicines [18]. Indeed, PCS is one of the most popular traditional medicines officially listed in the
"Chinese Pharmacopoeia" and has a variety of unique beneficial phytochemical constituents. The PCS seeds have been recently shown to have chemoprotective and antioxidant properties [19]. Some of its investigated phytochemicals showed phytoestrogenic [20], anti-inflammatory [21], and neuroprotective [22] properties. Moreover, the seed's aqueous extract was found to inhibit DA and NE transporters [23]. Such properties point the need to investigate benzopyrone moiety of the seeds for their MAO inhibitory effects.

In the current investigation, we selected six commonly known coumarins and flavonoids that share the benzopyrone structure (Fig. 1.). The selected coumarins included psoralen (PS), isopsoralen (IPS), and psoralidin (PSD). The selected flavonoids studied include 6-prenylnaringenin (6$\mathrm{PN})$, neobavaisoflavone (NBI), and biochanin-A (BIO-A). These benzopyrones are reported to be in PCS $[19,24]$. However, the $h \mathrm{MAO}-\mathrm{A}$ and $h \mathrm{MAO}-\mathrm{B}$ inhibitory effects and selectivities of these compounds remain to be elucidated. The need to find natural selective and reversible hMAO-B inhibitors motivated us to evaluate inhibitory activity and selectivity of six of PCS constituents with benzopyrone structures on human MAO-A and MAO-B.

\section{Methods \\ Reagents}

The tested pure PCS constituents ( $\geq 95 \%)$ of PS and PSD and the standard selective MAO-AI clorgyline (CLORG) were obtained from Santa Cruz Biotechnology Inc. (Dallas, TX, USA). Hank's Balanced Salt Solution (HBSS), HEPES, benzylamine $\mathrm{HCl}$, IPS, 6-PN, NBI, BIO-A, the selective MAO-BI standard selegiline (Deprenyl $\mathrm{l}^{\odot}$ ) (DEP), and other chemicals and chromatography supplies were purchased from Sigma-Aldrich (St Louis, MO, USA). Human MAO$\mathrm{A}$ and MAO-B, derived from a recombinant baculovirus infected insect cells, and measured in active units $(\mathrm{U})$ were purchased from Sigma-Aldrich and received in a buffer solution at $\mathrm{pH}$ 7.4. The China originated PCS were obtained from East Earth Trade Winds (Redding, CA, USA), and the MAO-Glo ${ }^{\mathrm{m}}$ kits from Promega (Madison, WI, USA).

\section{PCS extraction}

The dry PCS were milled and sieved into $30 \mathrm{~g}$ of fine seed powder and stored in a nitrogen-sealed container at $2^{\circ} \mathrm{C}$. To prepare PCSEE, we followed the procedure mentioned in our previous study [17]. Briefly, the fine PCS powder was macerated for two days using $99.95 \%$ ethanol. The extract was filtered and the powder obtained was subject to 8-10 h Soxhlet reflux extraction at $60^{\circ}$ to $70{ }^{\circ} \mathrm{C}$ with continuous solvent (ethanol) renewal every $2 \mathrm{~h}$. The combined ethanol extracts were evaporated in a dark hood to obtain an oily non-homogenous PCSEE. All the collected dry crude extracts and prepared PCS ethanolic stock solutions were stored in glass containers at $2{ }^{\circ} \mathrm{C}$ until use. 


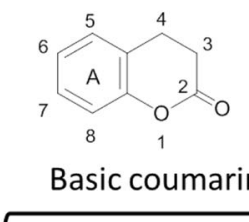

PS

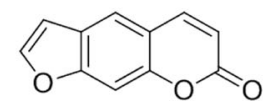

IPS<smiles>O=c1ccc2ccc3occc3c2o1</smiles>

PSD<smiles>CC(C)=CCc1cc2c(cc1O)oc(=O)c1cc(O)ccc12</smiles>

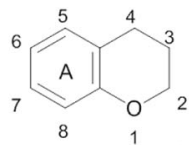

Basic benzopyrone structure

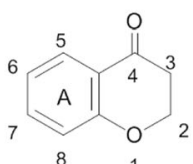

Basic chromone
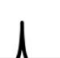<smiles>CC(C)=CCc1cc(-c2coc3cc(O)ccc3c2=O)ccc1O</smiles>

NBI<smiles>CC(C)=CCc1c(O)cc2c(c1O)C(=O)CC(c1ccc(O)cc1)O2</smiles>

6-PN<smiles>COc1ccc(-c2coc3cc(O)cc(O)c3c2=O)cc1</smiles>

Fig. 1 The structures of six Psoralea corylifolia seeds (PCS) benzopyrone constituents: Coumarins include psoralen (PS), isopsoralen (IPS), and psoralidin (PSD). Flavonoids of chromone structure include 6-prenylnaringenin (6-PN), neobavaisoflavone (NBI), and biochanin-A (BIO-A)

\section{hMAO-A and $h$ MAO-B enzymatic activity assays}

A slightly modified continuous spectrophotometric assay [25] for measuring enzymatic $\mathrm{H}_{2} \mathrm{O}_{2}$ production was validated before the experiments. In this assay, the peroxidase chromogen reagent of $1 \mathrm{mM}$ of vanillic acid and $500 \mu \mathrm{M}$ 4-aminoantipyrine, and $4 \mathrm{U}$ purpurogallin/mL of horseradish peroxidase (HRP) type-II in HBSS ( $\mathrm{pH}$ 7.4) was prepared and validated with $\mathrm{H}_{2} \mathrm{O}_{2}$ standard curve. The linearity of reaction on the instrument was confirmed to reach up to $1.76 \mathrm{nmol}$ per reaction volume with $\mathrm{R}^{2}$ of 0.9999 . Isozymes were diluted to $0.7 \mathrm{U} / \mathrm{mL}$ final concentration by $10 \mathrm{mM}$ HEPES in HBSS (pH 7.4). Substrates final concentrations were optimized to be 0.5 and $3 \mathrm{mM}$ tyramine $\mathrm{HCl}$ and benzylamine $\mathrm{HCl}$ for $h \mathrm{MAO}-\mathrm{A}$ and $h \mathrm{MAO}-\mathrm{B}$ reactions. The assay was run with and without different standard MAOIs with different selectivities (DEP, CLORG, pirlindole, and rasagiline) and monitored for few hours. Isozymes were found stable within the time of incubation. Stock solvents (ethanol or dimethyl sulfoxide) were kept $\leq 2 \%$ the final volume of all assays. $\mathrm{IC}_{50}$ s were measured at earliest readings with high signal to noise ratios possible were $\mathrm{H}_{2} \mathrm{O}_{2}$ formed $<10 \%$ for $h \mathrm{MAO}-\mathrm{A}$ and $h \mathrm{MAO}-\mathrm{B}$. For the confirmatory luminescence assay, using MAO-Glo ${ }^{\mathrm{TM}} \mathrm{kit}$, the protocol was followed to determining the time of incubation at $60 \mathrm{~min}$ at RT guided by Valley's method [26] and the preliminary experiments which we conducted.

\section{hMAO-A and $h$ MAO-B spectrophotometric assays}

The six benzopyrones of $5 \times$ final concentrations between 0 to $400 \mu \mathrm{M}$ and PCSEE from 0 to $250 \mu \mathrm{g} / \mathrm{mL}$ of at least ten data points were prepared in HBSS ( $\mathrm{pH} 7.4)$. The diluted compounds $(25 \mu \mathrm{L})$ were incubated with $50 \mu \mathrm{L}$ of $2.5 \times$ the final isozyme concentration (or buffer for blanks) in 96-96-good plates for $40 \mathrm{~min}$ at RT. Freshly prepared volumes of $50 \mu \mathrm{L}$ of $2.5 \times$ substrate and peroxidase chromogen mix (1:1) were added. Absorbance was immediately read at $490 \mathrm{~nm}$ by the Bio-Tek $\mu$ Quant Monochromatic Microplate Spectrophotometer for time zero. $\mathrm{H}_{2} \mathrm{O}_{2}$ production progression for each enzyme was measured every 20 min for the duration of the assay. First read measurements and the blanks background were subtracted from all absorbance values.

\section{hMAO-A and hMAO-B luminescence assay}

The six benzopyrones, PCSEE, and DEP inhibitory activities of $h \mathrm{MAO}-\mathrm{A}$ and $h \mathrm{MAO}-\mathrm{B}$ isozymes were confirmed using MAO-Glo ${ }^{\mathrm{TM}}$ kit luminescence assay. Briefly, in white opaque 96-well microplates, $12.5 \mu \mathrm{L}$ of $4 \times 10 \mu \mathrm{g} / \mathrm{mL}$ final concentrations of each test compound, standard DEP, or PCSEE in 
reaction buffer of $\mathrm{pH} 7.4$ were added ( $n=3$ per isozyme). A buffer of $12.5 \mu \mathrm{L}$ was used to make equivalent blank volumes of wells without enzyme. Equivalent amounts of used solvent volumes (ethanol or DMSO) were also added to separate wells. A volume of $25 \mu \mathrm{L}$ of $2 \times 0.9 \mathrm{U} / \mathrm{mL}$ final concentration of each of freshly thawed $h \mathrm{MAO}-\mathrm{A}$ and $h \mathrm{MAO}-\mathrm{B}$ isozymes were incubated with the test substances at RT. Freshly prepared luciferin derivative substrate volume of $12.5 \mu \mathrm{L}$ of $4 \times 40$ and $4 \mu \mathrm{M}$ the final concentrations were incubated for $60 \mathrm{~min}$ with $h \mathrm{MAO}-\mathrm{A}$ and $h \mathrm{MAO}-\mathrm{B}$ and inhibitors, respectively at RT. Reporter luciferase detects reagent of $50 \mu \mathrm{L}$ was incubated with each reaction for 20-30 min to inhibit the enzyme and produce luminescence. Arbitrary light units (ALU) signal changes were measured by Synergy HTX Multi-Reader from Bio-Tek and converted to percent control change.

\section{$\mathrm{H}_{2} \mathrm{O}_{2}$ scavenging activity assay}

The $\mathrm{H}_{2} \mathrm{O}_{2}$ scavenging activity of PCSEE and BIO-A at their highest used MAO inhibitory concentrations was investigated and compared to the standard scavenger Lascorbic acid. In 96 well plates, $25 \mu \mathrm{L}$ of $5 \times$ final concentration of PCSEE $(62.5,125$, and $250 \mu \mathrm{g} / \mathrm{mL})$, BIO-A $(6.25,12.5$, and $25 \mu \mathrm{g} / \mathrm{mL})$, and ascorbic acid $(62.5,125$, and $250 \mu \mathrm{g} / \mathrm{mL}$ ) in HBSS (7.4) were prepared. A volume of $75 \mu \mathrm{L}$ of $1.67 \times$ final concentration of $15 \mu \mathrm{M} \mathrm{H}_{2} \mathrm{O}_{2}$ in HBSS (7.4) was plated in test wells $(n=4)$. Buffer substituted the $\mathrm{H}_{2} \mathrm{O}_{2}(n=4)$ to make blank wells. Immediately, peroxidase chromogen-containing vanillic acid, 4aminoantipyrine, and HRP type-II were prepared as in the MAO spectrophotometric assay and added as $25 \mu \mathrm{L}$ per well. The developing color at $490 \mathrm{~nm}$ was optimally read within 15 min at RT using Bio-Tek Synergy HTX MultiReader absorbance.

\section{Fluorescent thin-layer chromatography analysis}

PCSEE and BIO-A were concurrently run on a silica gel matrix $\left(5 \times 10 \mathrm{~cm}^{2}\right)$ containing a fluorescent indicator with $254 \mathrm{~nm}$ excitation on aluminum foil (Sigma-Aldrich) for thin-layer chromatography (TLC) identification. On replicate TLC matrices, $5 \mu \mathrm{L}$ of a $1 \mathrm{~cm}$ short band of 20 $\mathrm{mg} / \mathrm{mL}$ PCSEE, and 1 and $5 \mathrm{mM}$ BIO-A (Sigma-Aldrich) ethanol stock solution were directly deposited at $0.5 \mathrm{~cm}$ or more from TLC plate lower edge. After ethanol evaporation, TLC plate was slowly placed and developed in a clean glass developing chamber saturated with a miscible solvent system (water: acetone: ethanol of 5: 3: 1 ratio), 0.5 $\mathrm{cm}$ deep or less. Plates were taken out after 50-60 min incubation at RT, or when solvent front reached $1 \mathrm{~cm}$ from the upper TLC edge (approximately $8.5 \mathrm{~cm}$ height). Dried developed TLC plates were then visualized under short $(254 \mathrm{~nm})$ and long $(366 \mathrm{~nm}) \mathrm{UV}$ lights. Retention factor $\left(\mathrm{R}_{f}\right)$ of BIO-A band and a matching band were quantified.

\section{$h M A O-A$ and $h$ MAO-B recovery}

$h \mathrm{MAO}-\mathrm{A}$ and $h \mathrm{MAO}-\mathrm{B}$ were tested for their activity recovery after preincubation with BIO-A, utilizing a slightly modified method reported by Legoabe et al [27] and using the continuous spectrophotometric assay [25]. Briefly, in HBSS medium $(\mathrm{pH} 7.4), \mathrm{BIO}-\mathrm{A}$ of $10 \times$ and $100 \times \mathrm{IC}_{50}$ and $\mathrm{DEP}$ at $10 \times \mathrm{IC}_{50}$ were preincubated separately with $70 \mathrm{U} / \mathrm{mL} h \mathrm{MAO}$ isozymes for $40 \mathrm{~min}$ at RT. BIO-A of $4 \times$ $\mathrm{IC}_{50}$ was concurrently preincubated with $0.7 \mathrm{U} / \mathrm{mL}$. Buffers substituted inhibitors and isozymes for negative controls and blanks, respectively. All reactions were diluted to 20 -fold. The $100 \times$ dilution was immediately accomplished by adding $50 \mu \mathrm{L}$ of the isozyme-inhibitor mixture to $75 \mu \mathrm{L}$ of related substrates-peroxidase chromogen reagent mix (a $25 \mu \mathrm{L}$ buffer and the original $50 \mu \mathrm{L}$ previously used a mixture) in a 96-well plate. By reaching $0.1 \times$ and $1 \times \mathrm{IC}_{50} \mathrm{BIO}-\mathrm{A}$ final concentration, developing color was immediately monitored using Bio-Tek $\mu$ Quant Spectrophotometer readings at RT.

\section{Michaelis-Menten kinetics}

The effects of BIO-A on Michaelis-Menten kinetics parameters of $h \mathrm{MAO}-\mathrm{A}$ and $h \mathrm{MAO}-\mathrm{B}$ were investigated using the same spectrophotometric assay mentioned above. Standard DEP was concurrently tested to validate the method. Determined DEP kinetics for $h \mathrm{MAO}-\mathrm{A}$ and $h \mathrm{MAO}-\mathrm{B}$ in the conditions of this experiment were determined and used as a standard for the Prism program validation for Inhibitor constant $\left(\mathrm{K}_{\mathrm{i}}\right)$ determination of BIO-A. Briefly, seven serially diluted tyramine and benzylamine concentrations were prepared in a range between 0 to $1 \mathrm{mM}$ for $h \mathrm{MAO}-\mathrm{A}$ and 0 to $6 \mathrm{mM}$ for $h \mathrm{MAO}-\mathrm{B}$. BIO-A for a final concentration of 0 , $0.5,1$, and $2 \times \mathrm{IC}_{50}$ concentrations were incubated with each isozyme for a final concentration of $0.7 \mathrm{U} / \mathrm{mL}$ in a $2: 1$ ratio $(0,1.7,3.4$ and $6.9 \mu \mathrm{M}$ for $h \mathrm{MAO}-\mathrm{A}$, and $0,0.05,0.09,0.19$ $\mu \mathrm{M}$ for $h \mathrm{MAO}-\mathrm{B})$. HBSS (pH7.4) substituted inhibitors and isozymes in the negative controls and the blanks, respectively. After $40 \mathrm{~min}, 75 \mu \mathrm{L}$ of the enzyme-BIO-A mixture were added to $50 \mu \mathrm{L}$ of the related substrate-chromogen reagent mix (1: 1) in 96-well plates. Developing color was monitored at RT using Bio-Tek $\mu$ Quant Spectrophotometer. Values of maximum velocity $\left(\mathrm{V}_{\max }\right)$, Michaelis constant $\left(\mathrm{K}_{\mathrm{m}}\right)$, and consequently Ki were determined.

\section{Molecular docking studies}

To understand the possible molecular interactions between BIO-A and isozymes active sites, we used the HYBRID docking method of OEDocking (v 3.0.1) (OpenEye Scientific Software Inc.; Santa Fe, NM, USA) [28]. Both Xray crystal structures of human (h) MAO-A in complex with harmine (PDB ID: 2Z5X) and human (h) MAO-B in complex with 2-(2-benzofuranyl)-2-imidazoline (2-BFI) (PDB ID: 2XFN) were downloaded from the RCSB Protein Data Bank (PDB). Both proteins structures were imported 
into Sybyl -X 1.3 environment of Tripos International (St. Louis, MO) where the protein's chain-A were extracted and refined using the Biopolymer Structure Preparation Tool. Atom types were corrected, amino acid residues were repaired, active water molecules were retained, and all hydrogen atoms were added to both proteins. The cofactor flavin adenine dinucleotide (FAD) and its covalent linkage to the cysteine residues of hMAO-A (CYS: 406: A), and hMAO-B (CYS: 397: A) were retained during the docking process. To be ready for the docking, the energy of each protein was minimized using the MMFF94 charges with the MMFF94s force fields. For docking the compound of interest (BIO-A), the low energy 3D conformers were generated using OMEGA version 2.4.6 of the same software [28]. The bound standard ligands of 2Z5X and 2XFN were sketched using Sybyl sketch and were re-docked to the crystal structures of the proteins for method validation. The root mean square deviation values between retrieved and re-docked poses of the ligands were less than $2 \AA$. Top ten poses were examined. BIO-A was then docked as a test ligand to both MAO proteins at their Ligand Binding Domain. The $\mathrm{H}$-bonds formed between BIO-A, and amino acid residues of the top poses were measured.

\section{Statistical analysis}

Statistical analyses were performed using GraphPad Prism program version 6.02 for Windows, GraphPad Prism Software Inc. (San Diego, CA, USA). Data points and parameters were expressed as the mean \pm SEM of all data. All parameters were calculated from non-linear regressions with the best $\mathrm{R}^{2}$ values. Inhibitory concentrations of $50 \%$ of isozyme $\left(\mathrm{IC}_{50}\right)$ were obtained by the interpolation of a normalized variable slope logarithmic curve. RS values of all benzopyrones and PCSEE were calculated from their mean $\mathrm{IC}_{50} \mathrm{~S}$ as follows:

$$
\begin{aligned}
\mathrm{RS}_{\mathrm{A}} & =h \mathrm{MAO}-\mathrm{B} \mathrm{IC} \mathrm{IC}_{50} / h \mathrm{MAO}-\mathrm{A} \mathrm{IC} \mathrm{IC}_{50}, \mathrm{RS}_{\mathrm{B}} \\
& =h \mathrm{MAO}-\mathrm{A} \mathrm{IC}{ }_{50} / h \mathrm{MAO}-\mathrm{IC}_{50}
\end{aligned}
$$

The $\mathrm{V}_{\max }$ and $\mathrm{K}_{\mathrm{m}}$ calculated from Michaelis-Menten kinetics model. $K_{i}$ was calculated according to the competitive behavior model as the best fit and Cheng-Prosuff's equation $\left(\mathrm{K}_{\mathrm{i} \text { (comp) }}=\mathrm{IC}_{50} /\left(1+[\mathrm{S}] / \mathrm{K}_{\mathrm{m}}\right)\right)$. SI of BIO-A was calculated from mean $\mathrm{K}_{\mathrm{i}}$ values $\left(\mathrm{SI}=h \mathrm{MAO}-\mathrm{A} \mathrm{K}_{\mathrm{i}} / h \mathrm{MAO}\right.$ $\left.B K_{i}\right)$. The significance of differences between the different groups was determined using one-way ANOVA followed by Dunnett's multiple comparisons test or two-way ANOVA followed by Sidak's multiple comparisons test.

\section{Results}

\section{PCS benzopyrones Inhibition of $h M A O-A$ and $h$ MAO-B}

To investigate the hMAO-A and $h \mathrm{MAO}-\mathrm{B}$ inhibitory effects of the six PCS benzopyrones constituents, we determined their enzymatic $\mathrm{H}_{2} \mathrm{O}_{2} \mathrm{IC}_{50} \mathrm{~s}$ using a spectrophotometric assay (Fig. 2 Table) and verified their inhibition by a luminescence assay (Fig. 2 a and b). In both assays, solvents used in compounds stocks showed no significant difference from the controls without solvents. From the first glance at the Table of Fig. 2, benzopyrones of flavonoids and coumarins results clearly indicate an array of $h \mathrm{MAO}-\mathrm{A}$ and $h \mathrm{MAO}-\mathrm{B}$ inhibition potencies with $h \mathrm{MAO}-\mathrm{A}$ and $h \mathrm{MAO}-\mathrm{B} \mathrm{IC}_{50} \mathrm{~s}$ less than $\sim 100$ and $\sim 200$ $\mu \mathrm{M}$, respectively. Compared with standards CLORG and DEP, $h$ MAO-A $\mathrm{IC}_{50} \mathrm{~S}$ of the benzopyrones showed BIO$\mathrm{A}>\mathrm{IPS}>6-\mathrm{PN}>\mathrm{NBI}>\mathrm{PS}>\mathrm{PSD}$ (no detectable inhibition), with IPS, PS, and NBI having a relative selectivity to inhibit $h \mathrm{MAO}-\mathrm{A} \quad\left(\mathrm{RS}_{\mathrm{A}}\right)$. Meanwhile, $h \mathrm{MAO}-\mathrm{B} \quad \mathrm{IC}_{50} \mathrm{~S}$ showed $\mathrm{BIO}-\mathrm{A}>6-\mathrm{PN}>\mathrm{IPS}>\mathrm{NBI}>\mathrm{PS}>\mathrm{PSD}$ (partial inhibition, $p<0.001$ ), with $\mathrm{BIO}-\mathrm{A}$ and $6-\mathrm{PN}$ having a relative selectivity in favor to inhibit $h \mathrm{MAO}-\mathrm{B}\left(\mathrm{RS}_{\mathrm{B}}\right)$. In this assay, $\mathrm{BIO}-\mathrm{A}$ was, by far, the most potent and selective $h \mathrm{MAO}-\mathrm{B}$ inhibitor among the six tested benzopyrones.

All the six benzopyrones activities against $h \mathrm{MAO}-\mathrm{A}$ and $h \mathrm{MAO}-\mathrm{B}$ were further confirmed at a fixed concentration using MAO-Glo ${ }^{\mathrm{Ts}}$ kit luminescence assay, a highly sensitive and an $\mathrm{H}_{2} \mathrm{O}_{2}$-independent technique (Fig. $2 \mathrm{a}$ and b). Standard DEP and PCSEE were used as positive controls. All benzopyrones at $10 \mu \mathrm{g} / \mathrm{mL}$ are differently affected $h M A O-\mathrm{B} h \mathrm{MAO}-\mathrm{A}(p \leq 0.05$ to 0.0001$)$, confirming the inhibitory array pattern of the spectrophotometric assay with even higher inhibitory effects. Consistent with our spectrophotometric assay selectivity data, IPS, PS, and $\mathrm{NBI}$, were more effective against $h \mathrm{MAO}-\mathrm{A}$, and 6-PN was more effective against $h M A O-\mathrm{B}$, while $\mathrm{BIO}-\mathrm{A}$ selectivity was masked by its highly potent effects using luminescence. Thus, the relative selectivity of benzopyrones matching the spectrophotometric assay is an indication that these benzopyrones possess $h \mathrm{MAO}-\mathrm{A}$ and $h \mathrm{MAO}-\mathrm{B}$ inhibitory effects with different selectivities.

\section{BIO-A and PCSEE Inhibition of $h M A O-A$ and $h M A O-B$}

To compare the BIO-A inhibitory potencies of $h \mathrm{MAO}-\mathrm{A}$ and $h \mathrm{MAO}-\mathrm{B}$ with PCSEE inhibitory potencies, we elucidated PCSEE effects on both isozymes $\mathrm{H}_{2} \mathrm{O}_{2}$ production using the same spectrophotometric assay (Fig. 3). Ethanol concentrations did not have effects on control isozymes activities. The PCSEE treatments significantly inhibited both isozymes $(p<0.0001)$ (Fig. 3 a). PCSEE showed $\mathrm{RS}_{\mathrm{B}}$ (17.3-fold) with an $\mathrm{IC}_{50}$ of $3.03 \mu \mathrm{g} / \mathrm{mL}$ (hMAO-B) compared to $52.36 \mu \mathrm{g} / \mathrm{mL}$ (hMAO-A). Nevertheless, the left shifted BIO-A curves compared to PCSEE curves display BIO-A significantly higher potency and $\mathrm{RS}_{\mathrm{B}}$ than PCSEE (Fig. $3 \mathrm{~b}$ ).

\section{BIO-A and PCSEE $\mathrm{H}_{2} \mathrm{O}_{2}$ scavenging activity}

$\mathrm{H}_{2} \mathrm{O}_{2}$ scavenging activities were tested to reveal BIO-A and PCSEE direct effects on the enzymatic $\mathrm{H}_{2} \mathrm{O}_{2}$ or other side 


\begin{tabular}{|c|c|c|c|c|}
\hline Compound & $\begin{array}{l}h \mathrm{MAO}-\mathrm{A} \\
\mathrm{IC}_{50}[\mu \mathrm{M} \pm \mathrm{SEM}]\end{array}$ & $\begin{array}{l}h \mathrm{MAO}-\mathrm{B} \\
\mathrm{IC}_{50}[\mu \mathrm{M} \pm \mathrm{SEM}]\end{array}$ & $\mathrm{RS}_{\mathrm{A}}$ & $\mathrm{RS}_{\mathrm{B}}$ \\
\hline PS & $89.04 \pm 5.74$ & $174.80 \pm 50.9$ & 2.0 & \\
\hline IPS & $20.62 \pm 2.45$ & $51.00 \pm 0.24$ & 2.5 & \\
\hline NBI & $66.52 \pm 5.66$ & $77.29 \pm 10.65$ & 1.2 & \\
\hline $6-\mathrm{PN}$ & $54.53 \pm 0.31$ & $17.93 \pm 1.84$ & & 3.0 \\
\hline BIO-A & $3.43 \pm 0.31$ & $0.09 \pm 0.01$ & & 38.1 \\
\hline PSD & ND & ND & - & - \\
\hline DEP & $1.88 \pm 0.29$ & $0.013 \pm 0.001$ & & 144.6 \\
\hline CLORG & $0.0006 \pm 0.0001$ & $49.66 \pm 7.47$ & 82,767 & \\
\hline
\end{tabular}
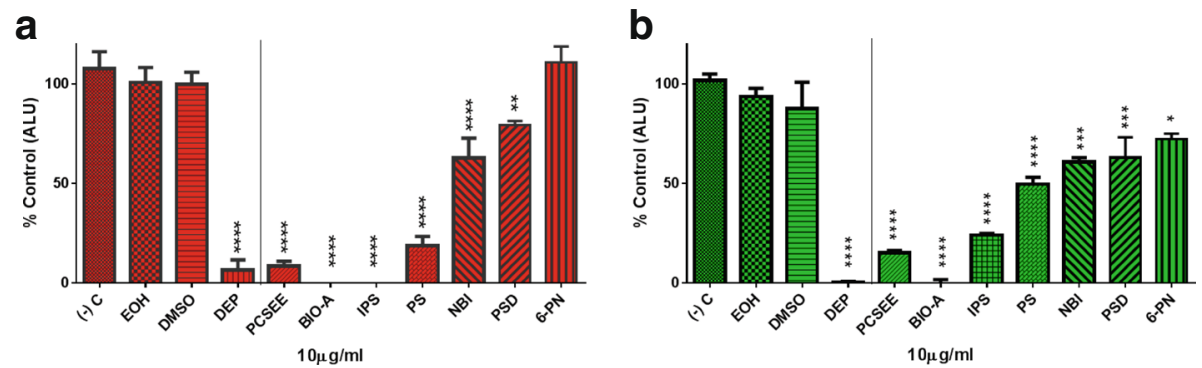

Fig. 2 Inhibition potencies and selectivity of $h M A O-A$ and $h M A O-B$ by PCS benzopyrone constituents. The Table displays IC F0 $_{5}$ of BIO-A, PS, IPS, 6-PN, $\mathrm{NBI}$, and PSD compared with standards deprenyl (DEP) and clorgyline (CLORG), with relative selectivity for isozymes $A\left(R_{A}\right)$ and $B\left(R_{B}\right)$, using a spectrophotometric assay. a hMAO-A and (b) hMAO-B confirmation of inhibition by the six benzopyrones compared to PCSEE, DEP, and solvents of ethanol $(E O H)$ and DMSO using a luminescence assay. $\mathrm{I}_{50} \pm \mathrm{SEM}$ is interpolated from two sigmoidal curves, and data points were presented as the mean \pm SEM percentage isozyme activity of at least two independent experiments of $n=3$. $\mathrm{RS}_{A}$ and $\mathrm{RS}_{B}$ are the ratio between high isozyme $I_{50}$ to the low $I_{50}$. Significances of differences between groups and control were determined using a one-way ANOVA followed by Dunnett's multiple comparisons test. ${ }^{*} p \leq 0.05,{ }^{* * *} p<0.001$

interactions with the hMAOs assays (Fig. 3 c). The ascorbic acid standard showed a complete scavenging activity at all tested concentrations $(p<0.001)$. However, the high tested concentrations of BIO-A and PCSEE did not show any scavenging activities. Moreover, PCSEE increased the $\mathrm{H}_{2} \mathrm{O}_{2}$ signal $(p \leq 0.05)$ which may indicate other autoxidation reactions that occur only at a very high concentration of $250 \mu \mathrm{g} / \mathrm{mL}$. The results suggest that the inhibition of enzymatic $\mathrm{H}_{2} \mathrm{O}_{2}$ by BIO-A and PCSEE were solely by the mechanism of inhibiting $h \mathrm{MAO}-\mathrm{A}$ and $h \mathrm{MAO}-\mathrm{B}$, and not by $\mathrm{H}_{2} \mathrm{O}_{2}$ scavenging activities.

\section{Identification of BIO-A in PCSEE}

BIO-A identification was verified in the PCSEE extract using the fluorescent silica gel TLC and our optimized developing system (Fig. 3 d). BIO-A's non-fluorescent dark band on the TLC plate matched a non-fluorescent dark band in PCSEE fingerprint at both UV excitation waves. At $366 \mathrm{~nm}, \mathrm{BIO}-\mathrm{A}$ band $(R f=0.36 \pm 0.002)$ was visibly matching one of the PCSEE dark bands $(R f=0.37 \pm 0.002)$ at similar conditions $(p>0.05)$. At $254 \mathrm{~nm}$ with $\mathrm{BIO}-\mathrm{A}$ increased concentration, BIO-A dark band matched a nonfluorescent dark band in the PCSEE fingerprint developed bands. Thus, in addition to its identification of the used seeds, the chromatographic method supported the reported presence of BIO-A as one of PCS phytochemicals.

\section{hMAO-A and $h$ MAO-B modes of inhibition by BIO-A}

To determine the isozymes mode(s) of inhibition by BIO-A, reversibility of inhibition, Michaelis-Menten parameters changes, $\mathrm{K}_{\mathrm{i}}$ values for $h \mathrm{MAO}-\mathrm{A}$ and $h \mathrm{MAO}-\mathrm{B}$, are presented in Figs. 4, and 5, respectively.

\section{$h M A O-A$ and $h M A O-B$ reversibility of inhibition by BIO-A}

To determine if $\mathrm{BIO}-\mathrm{A}$ is a reversible $h \mathrm{MAO}-\mathrm{A}$ and $h \mathrm{MAO}-\mathrm{B}$ inhibitor, we tested the recovery of both isozymes from BIO-A inhibition after dilution (Fig. 4 a, and b), with time monitoring (Fig. $4 \mathrm{c}$ and d). Compared to controls, the $0.1 \times \mathrm{IC}_{50}$ of standard DEP reduced both isozymes activities to $7 \%$ (with $h \mathrm{MAO}-\mathrm{A}$ ), and $51 \%$ (with $h \mathrm{MAO}-\mathrm{B}$ ) instead of $90 \%$, respectively. That is an indication of possible slow, partial, or no recovery of the isozymes from DEP inhibition at the experimental conditions. With $h \mathrm{MAO}-\mathrm{B}$, repeatedly unexpected observed high signal with DEP could be due to interactions with $h$ MAO-B sample contaminants at very elevated levels of drug and enzyme. Conversely, in similar preincubation conditions of BIO-A with $h \mathrm{MAO}-\mathrm{A}$ and 
a
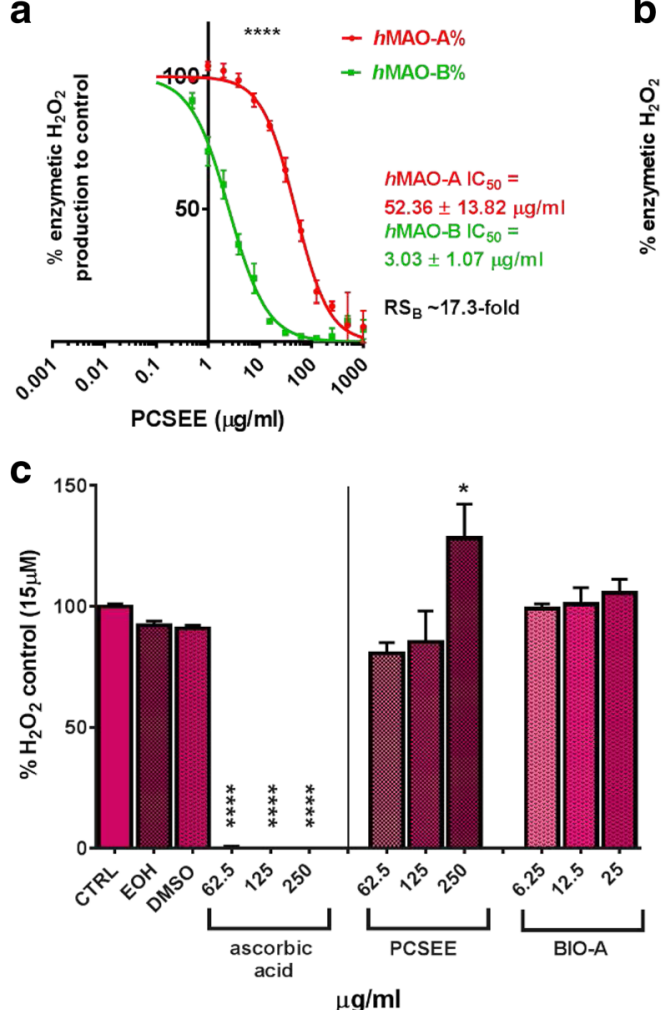

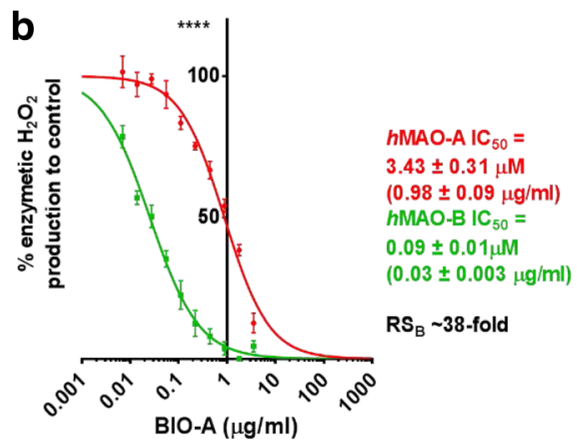

d

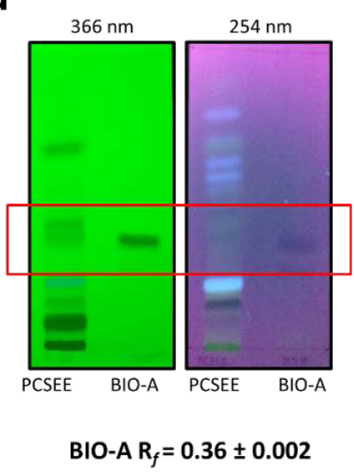

Fig. 3 BIO-A and PCSEE selectively inhibited $\mathrm{H}_{2} \mathrm{O}_{2}$ produced by $h M A O-B$ more than $h M A O-A$ using a spectrophotometric assay without scavenging $\mathrm{H}_{2} \mathrm{O}_{2}$, (a) PCSEE inhibited both isozymes from producing $\mathrm{H}_{2} \mathrm{O}_{2}$, and inhibits $h M A O-B$ selectively. b BIO-A inhibited $h M A O-A$ and hMAO-B with a higher potency and $h M A O-B$ selectivity $\left(\mathrm{RS}_{\mathrm{B}}\right)$ than PCSEE. $\mathbf{c} \mathrm{H}_{2} \mathrm{O}_{2}$ scavenging activity by PCSEE and BIO-A compared to ascorbic acid. d Fluorescent TLC plate of PCSEE fingerprint and a BIO-A matching band ( $R_{f} \pm$ SEM) visualized under UV waves. Data points were presented as the mean \pm SEM, $n=3(\mathbf{a}, \mathbf{b}), 4(\mathbf{c})$, and $6(\mathbf{d}) I_{50} \pm$ SEM is interpolated from two sigmoidal curves averages. Significance of differences between hMAO-A and hMAO-B inhibition curves in (a) and (b) were determined using a two-way ANOVA followed by Sidak's multiple comparisons test, and between control and treatments in (c) using one-way ANOVA followed by Dunnett's multiple comparisons test; ${ }^{*} p \leq 0.05,{ }^{* * * *} p<0.001$

hMAO-B, dilution allowed a complete or an almost complete recovery of activities. The $h \mathrm{MAO}-\mathrm{A}$ (Fig. 4 a) and $h$ MAO-B (Fig. 4 b) catalytic rates with 1 and $0.1 \times$ $\mathrm{IC}_{50}$ BIO-A were $\sim 50 \%$ and $\sim 90 \%$, respectively. Both isozymes constant recovery with time (Fig. $4 \mathrm{c}$ and $\mathrm{d}$ ) is a character of a reversible inhibitor, as the activities of recovered enzymes were similar to the enzymes subjected directly to 1 or $0.1 \times \mathrm{IC}_{50}$ of $\mathrm{BIO}-\mathrm{A}$. The obtained results demonstrate evidence that $\mathrm{BIO}-\mathrm{A}$ is a reversible inhibitor of $h \mathrm{MAO}-\mathrm{A}$ and $h \mathrm{MAO}-\mathrm{B}$.

\section{BIO-A-induced changes of $h$ MAO-A and $h$ MAO-B Michaelis-Menten parameters}

To determine the mode of $\mathrm{BIO}-\mathrm{A}$ reversible inhibition on both MAOs, we investigated BIO-A effects on Michaelis-Menten kinetics of $h \mathrm{MAO}-\mathrm{A}$ and $h \mathrm{MAO}-\mathrm{B}$ at their initial velocities (Fig. 5). In Fig. 5 a and b, Lineweaver-Burk plot linear regressions for the BIO-A increased $\mathrm{IC}_{50}$ fold co-intersected at the $\mathrm{Y}$-axis indicating a competitive mode of inhibition in both isozymes.
Compared to control in Table of Fig. 5 c, BIO-A showed no significant change in $h \mathrm{MAO}-\mathrm{A} \mathrm{V}_{\max }$ while $\mathrm{K}_{\mathrm{m}}$ values significantly $(p<0.001)$ geometrically doubled (9.54, 19.66, 40.38-fold, respectively) with increasing BIO-A $\mathrm{IC}_{50} \mathrm{~s}$ fold of concentrations. Similarly, $h \mathrm{MAO}-\mathrm{B} \mathrm{V}_{\max }$ showed no significant changes while benzylamine $K_{m}$ values were significantly $(p<0.01)$ nearly linearly increased (3.33-, 6.76-, 10.18- fold respectively) with the BIO-A doubled $\mathrm{IC}_{50} \mathrm{~S}$. The obtained data indicate the competitiveness of BIO-A to inhibit both isozymes.

\section{BIO-A $K_{i}$ and SI determination}

To confirm competitiveness of BIO-A for hMAO-A and $h \mathrm{MAO}-\mathrm{B}$ inhibitions, and consequently determine BIO-A $\mathrm{K}_{\mathrm{i}}$ and its $h \mathrm{MAO}-\mathrm{B}$ selectivity index (SI), we analyzed Michaelis-Menten data by best-fit enzyme inhibitory models using GraphPad Prism. (Fig. 5 d; Table). The mixed enzyme inhibition model for standard DEP indicated a competitive inhibitory mode for $h \mathrm{MAO}-\mathrm{A}$ (alpha $>1$ ) and a noncompetitive mode for $h \mathrm{MAO}-\mathrm{B}$ inhibition (alpha $\sim 1$ ). 

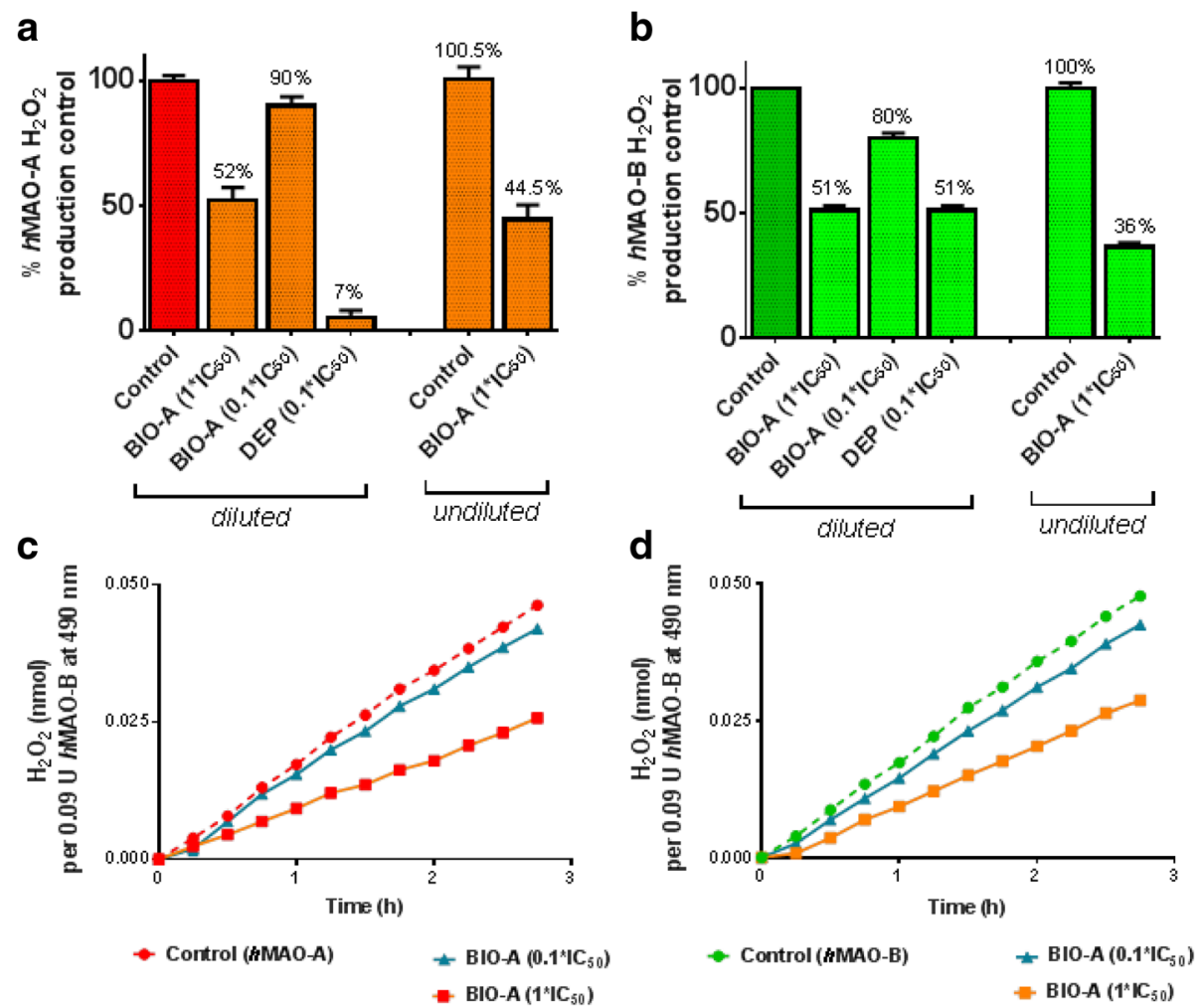

Fig. 4 hMAOs isozymes recoveries after BIO-A dilution: hMAO-A (a) and hMAO-B (b) recovery after preincubation of BIO-A diluted 100-fold to $1 \times$ or $0.1 \times I_{50}$, compared to diluted standard DEP, and undiluted inhibition data. hMAO-A (c) and hMAO-B (d) recoveries were monitored with time at RT. Data points, representing two experiments, and parameters, representing the average of two experiments, at least, were expressed as the mean \pm SEM, $n=3$

Meanwhile, the same model supported that BIO-A impedes substrate-binding affinity to both isozymes (alpha $>>1$ ). Thus, the analysis confirms BIO-competitiveness for both isozymes and rejects the non-competitive, uncompetitive behavior. Consequently, BIO-A $\mathrm{K}_{\mathrm{i}}$ values showed that BIO-A SI has a tight affinity to bind to $h \mathrm{MAO}-\mathrm{B}$ more than hMAO-A (26-fold; $p<0.001)$.

\section{Molecular docking of BIO-A}

To recognize the molecular level of the interactions of $\mathrm{BIO}-\mathrm{A}$ with the amino acids in the active site involved in its MAOs reversible and competitive inhibitions; we conducted a molecular docking study on both isozymes (Fig. 6). BIO-A was well docked to the same human MAO-A and $h \mathrm{MAO}-\mathrm{B}$ crystal structure active sites at which $2 \mathrm{Z} 5 \mathrm{X}$ and 2XFN interacted, respectively (Fig. 6). In the MAO-A compact active site cavity, BIO-A matched the $2 \mathrm{Z} 5 \mathrm{X}$ pose with its C3-phenyl ring and the chromone core structure embedded in the hydrophobic zone of the entrance site (Fig. 6 a, Brown zone). Also, BIO-A was predicted to be a donor for a relatively tight $\mathrm{H}$-bond (1.99 $\AA$ ) formed between the hydrogen of its $\mathrm{C} 7-\mathrm{OH}$ group and the nitrogen FAD of the enzyme (Fig. $6 \mathrm{c}$ Table). Therefore, the reversible H-bond with FAD and the hydrophobic interactions at the entrance cavity may contribute to $\mathrm{BIO}-\mathrm{A}$ reversible competitive behavior in effectively inhibiting human MAO-A.

Nonetheless, $\mathrm{BIO}-\mathrm{A}$ showed stronger interactions at the active site of MAO-B than MAO-A. All of the BIO-A i.e., the lipophilic chromone core structure, the C3-phenyl ring, and possibly the methyl group of C4' positions, were completely embedded in the MAO-B active site lipophilic zones, away from the FAD (Fig. 6 b, Brown zone). Notably, $\mathrm{BIO}-\mathrm{A}$ was predicted to be a donor and an acceptor for two distant $\mathrm{H}$-bond. One at the entrance cavity between the oxygen acceptor of its $\mathrm{C}^{\prime}-\mathrm{OCH}_{3}$ group and the active water molecule, and the other, is closer to the substrate cavity between the carbon donor of its $\mathrm{C} 7-\mathrm{OH}$ and the Leucine 164 (Fig. 6 c Table). The BIO-A H-bond distances were close to the 2XFN H-bond distances. The predicted reversible hydrophobic interactions and distant $\mathrm{H}$-bonds formations might consistently reflect the high affinity, reversibility, and competitiveness extent of BIO-A towards its MAO-B mode of inhibition.

\section{Discussion}

As part of our search for safe, natural MAO-B inhibitors, and guided by selecting benzopyrone structures, we focused our efforts to investigate compounds that could 


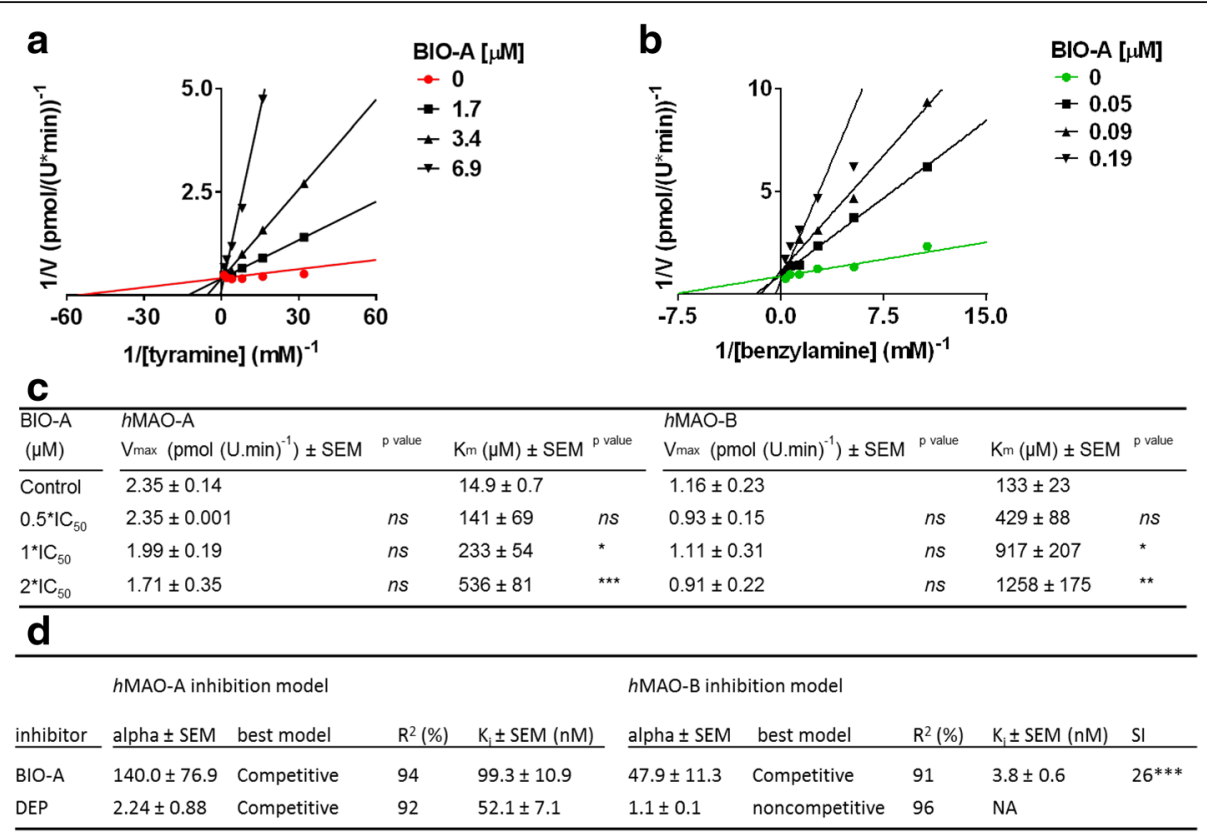

Fig. 5 BIO-A effects on Michaelis-Menten Kinetics of hMAO-A and hMAO-B isozymes: Representative Lineweaver-Burk (LWB) plots of hMAO-A (a) and $h M A O-B(\mathbf{b})$ at their initial velocity $(V)$ with increasing tyramine and benzylamine substrates at RT. $\mathbf{c}$ The effects of BIO-A on the parameters of maximum velocity $\left(V_{\max }\right)$ and Michaelis constant $\left(K_{m}\right)$ average values in both isozymes. $\mathbf{d}$ Following alpha results, inhibitor constant $\left(K_{i}\right)$ was calculated using the competitive model and compared to standard DEP: not applicable (NA) for the competitive model. Data points were expressed as the mean $\pm \mathrm{SEM}, n=3$, representing two experiments. Parameters data are the average of at least two experiments. The significance of the difference between the control and treatments was determined using a one-way ANOVA followed by Dunnett's multiple comparisons test, or between two groups using unpaired t test. ns: non-significant, ${ }^{*} p \leq 0.05,{ }^{* *} p<0.01,{ }^{* * *} p<0.001$

be responsible for the plant PCS selective MAO-B inhibition. Furthermore, we characterized the action of the most potent and selective inhibitor. In the current investigation, we tested PCS as well as six of its benzopyrone constituents for their $h \mathrm{MAO}-\mathrm{A}$ and $h \mathrm{MAO}-\mathrm{B}$ inhibitions. The PCS isoflavone constituent BIO-A was found to be the most potent and selective $h \mathrm{MAO}-\mathrm{B}$ inhibitor in this study. BIO-A was also more potent and selective than PCSEE. The presence of BIO-A in PCSEE was verified, and their inhibition of MAOs did not involve $\mathrm{H}_{2} \mathrm{O}_{2}$ scavenging activity. Furthermore, our results indicated that BIO-A is a reversible and competitive $h \mathrm{MAOI}$ with an SI to inhibit $h \mathrm{MAO}-$ B. In molecular docking experiments, BIO-A selective activity was accompanied with two reversible $\mathrm{H}$-bonds and three hydrophobic interactions with the human MAO-B active site, which were more than the reversible interactions formed with the MAO-A active site.

The results obtained showed that BIO-A (5, 7-dihydroxy4'-methoxyisoflavone) is the most potent $h \mathrm{MAO}-\mathrm{A}$ and $h \mathrm{MAO}-\mathrm{B}$ inhibitor with the highest MAO-B selectivity out of the tested benzopyrones and PCSEE (Figs. 2 and 3). The obtained PCSEE results are consistent with our previous reports on the potency and selectivity using spectrophotometric and fluorescence assays with different extraction methods $[15,16]$. We verified the presence of BIO-A in our used PCSEE to confirm previously reported $0.063 \pm 0.003 \%$ $\mathrm{w} / \mathrm{w}$ of BIO-A in the dried PCS [24]. BIO-A $\mathrm{IC}_{50}$ and RS results on both isozymes were consistent with the more reflective parameter of its binding affinity, $\mathrm{K}_{\mathrm{i}}$; that was higher in hMAO-B than hMAO-A (Fig. 5). Notably, BIO-A at a very high concentration becomes less selective due to the structure similarities of both isozymes (Figs. 2 and 3). Similarly, standards pirlindole, DEP, and RAS become nonselective when their concentrations are highly increased.

The obtained results indicate the non-selectivity of the studied coumarins as MAOIs. These results are supported by previous reports which indicate PCS total furocoumarins had antidepressant effects in mice and showed in vitro rat MAOs inhibitory effects [29], and another study reported PS and IPS inhibitory effects of rat MAOs [30]. Additionally, we used luminescence assay for confirmation of spectrophotometric assay isozymes effective inhibitions; the luminescence assay is independent of measuring $\mathrm{H}_{2} \mathrm{O}_{2}$ with a lower representation of the biological reactions. The varied inhibitory potencies may differ with the enzyme source and methods used as it was previously reported with other MAO-BIs [31].

BIO-A structure and the tested benzopyrones are absent of any reactive terminal amino groups as in DEP or phenelzine that can covalently bind at the MAO active site. Our docking evaluation indicated that the non-covalent molecular interactions were underlying BIO-A competitiveness for 

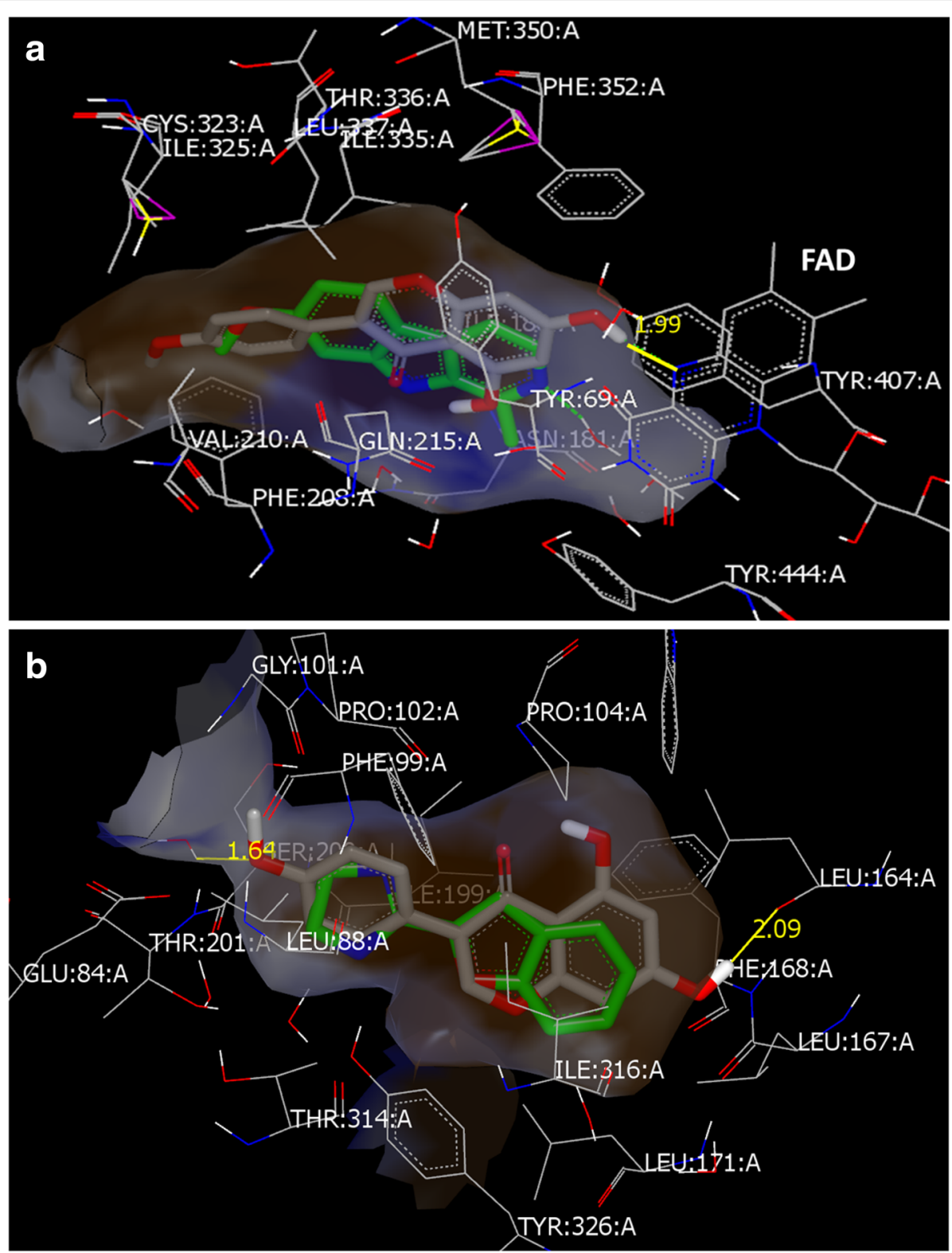

\begin{tabular}{|c|c|c|c|c|c|c|c|c|c|}
\hline \multirow[b]{2}{*}{ Ligand $^{\mathrm{a}}$} & \multicolumn{4}{|c|}{ MAO-A H-bonds } & \multicolumn{4}{|c|}{ MAO-B $\quad$ H-bonds } & \multirow{2}{*}{$\begin{array}{c}\text { MAO } \\
\text { selectivity }\end{array}$} \\
\hline & predicted & $\mathrm{A}^{\circ}$ & type $^{b}$ & active residue & predicted & $\mathrm{A}^{\circ}$ & type $^{\mathrm{b}}$ & active residue & \\
\hline \multirow{2}{*}{ BIO-A } & 1 & 1.99 & $\mathrm{OH} . . . \mathrm{N}$ & $\mathrm{FAD}$ & 2 & 1.64 & $\mathrm{O} \ldots \mathrm{HO}$ & $\mathrm{H}_{2} \mathrm{O}$ & \multirow{2}{*}{ B } \\
\hline & & & & & & 2.09 & CH...O & LEU: 164: A & \\
\hline $2 \mathrm{Z} 5 \mathrm{X}$ & 1 & 1.61 & $\mathrm{~N} . . \mathrm{HO}$ & $\mathrm{H}_{2} \mathrm{O}$ & & & & & A \\
\hline \multirow[t]{2}{*}{$2 \mathrm{XFN}$} & & & & & 2 & 1.80 & $\mathrm{NH} \ldots \mathrm{O}$ & PRO: 102: A & \multirow[t]{2}{*}{ B } \\
\hline & & & & & & 2.00 & $\mathrm{~N} . . . \mathrm{HO}$ & TYR: 326: A & \\
\hline
\end{tabular}

Fig. 6 BIO-A docking orientations within human MAO-A and MAO-B crystal structure active sites (BIO-A is a gray molecule, active sites: the neutral zones are gray, the lipophilic zones are brown, and the hydrophilic zones are blue in color): (a) within MAO-A with 2Z5X_ligand standard (in green), and (b) within MAO-B with 2XFN_ligand standard (in green). In table (c), predicted BIO-A H-bonds numbers, distances ( $\AA$ ), type of $\mathrm{H}$-bonds between BIO-A (on left) and residue (on right) $\left({ }^{b}\right)$, and involved amino acid residues are compared to the two standard ligands docked within the same site ${ }^{(}{ }^{\mathrm{a}}$. Key: LEU: leucine, PRO: proline, TYR: tyrosine at the A chain of MAO-B 
hMAO-A and hMAO-B (Fig. 5), and thus, supported our biochemical data. In the human MAO-B, BIO-A contained two $\mathrm{H}$-bonds comprising the acceptor and the donor of the $\mathrm{C} 7-\mathrm{OH}$ and the $\mathrm{C}^{\prime}-\mathrm{OCH}_{3}$ groups, respectively (Fig. 1). Previous docking studies indicated that flavonoids $\mathrm{H}$-bond donors or acceptors complemented with lipophilic interactions are candidates to modulate both rat MAOs activities [32]. Additionally, two predicted H-bonds at $h \mathrm{MAO}-\mathrm{B}$ in our previous reports of flavonoids bavachinin and genistein were accompanied with competitive $h \mathrm{MAO}-\mathrm{B}$ inhibitory effects with higher $h \mathrm{MAO}-\mathrm{B}$ affinity than MAO-A $[17,33]$. Thus, the two H-bond acceptors with the three hydrophobic groups in BIO-A held the best features of the MAO-BI flavonoid pharmacophore more than MAO-A. These consistent results point out $\mathrm{H}$-bonds as a possible critical factor for the human MAO-B affinity stabilization and consequently a better flavonoid inhibitory activity. In MAO-A however, the prediction of a single but crucial $\mathrm{H}$-bond with FAD may explain BIO-A lower affinity, potency, and higher competitiveness to inhibit MAO-A than B.

In addition to our results in $h \mathrm{MAO}-\mathrm{A}$ and $h \mathrm{MAO}-\mathrm{B}$ inhibitions, BIO-A was reported to have several multiple pharmacological functions. BIO-A was reported to be neuroprotective in in-vitro and in vivo studies through its multimechanistic antiinflammatory, antioxidant, and phytoestrogenic properties. BIO-A inhibited lipopolysaccharide (LPS)-induced dopaminergic cell damage in rats [34], and LPS-induced activation of microglia [35], protected from the glutamate- and $A \beta$ - induced cytotoxicity in neuropathological rat models $[36,37]$, and the glutamateinduced cytotoxicity in human cortical neurons [38].

More importantly, BIO-A ameliorated age- and druginduced cognitive and behavioral dysfunctions in mice model [39], improved the neuronal viability, vascular functions, and memory [40], and promoted the recovery of peripheral nerve injuries [41] in rat models. It also reduced acetylcholinesterase in dementia mouse [40] and rat [39] models. Such reports indicate that BIO-A can provide neuroprotective effects in different animal models and provide evidence that BIO-A can cross the blood-brain barrier. From another perspective, BIO-A was reported of being metabolized by 4'-O-demethylation by $\mathrm{P} 450$ isoforms mainly CYP1A2 to genistein [42, 43]. Moreover, genistein was also reported to be metabolized back to BIO-A by 4'O-methylation by rat liver enzymes [44]. Furthermore, in our recent investigations, genistein was found to be an active MAOI [33]. BIO-A with its metabolite genistein shared hepatoprotective [45], antimicrobial [46], and anticancer activities [44]. Having BIO-A and genistein to be human MAOIs, the two analogs mutual presence is highly possible in the blood, and hence, their possible activity in the brain against neurodegeneration.

The present kinetics studies indicate that BIO-A can be a safe and effective MAO-BI. The relatively superior selectivity of BIO-A can eliminate oxidative stress produced by both $\mathrm{H}_{2} \mathrm{O}_{2}$ and toxic aldehydes, which are generated by $h \mathrm{MAO}-$ B. The reversibility and competitiveness of BIO-A for hMAOs inhibitions can also eliminate the classical side effects related to MAOIs irreversibilities such as the cheese effect, psychosis, withdrawal and possible drug interactions. Consequently, BIO-A may safely reduce the aging brain oxidative stress by introducing a new mechanism for reversibly inhibiting both human MAOs with MAO-B inhibitory selectivity. There are other natural products with MAO-B inhibition proposed for neuroprotection [47-49], and there is a need to disclose their value in $\mathrm{PD}$ and $\mathrm{AD}$ patients.

\section{Conclusions}

It was concluded from the current study that BIO-A as a PCS benzopyrone constituent was found to be the most potent and selective human MAO-B inhibitor among the studied benzopyrones. BIO-A, and the variable $h \mathrm{MAO}-\mathrm{A}$ and $h \mathrm{MAO}-\mathrm{B}$ inhibitions of benzopyrones may partially explain the PCSEE MAO-B inhibition potency and selectivity. The results also indicated that BIO-A is a reversible and competitive MAOI with a high selectivity index and high affinity to inhibit MAO$\mathrm{B}$. The predicted interactions of BIO-A with the active site amino acids involve reversible $\mathrm{H}$-bonds and hydrophobic interactions instead of irreversible covalent adducts. This combined mechanism of MAO-B selectivity and reversibility may provide a greater safety margin and prevent the classical MAOIs side effects and following drug restrictions. Supported by previous reports, our data highlights BIO-A potentials to be used for the management of age-related neurodegenerative diseases such as PD, and AD.

\section{Abbreviations}

6-PN: 6-prenylnaringenin; AD: Alzheimer's disease; BIO-A: Biochanin A; CLOG: Clorgyline; DA: Dopamine; DEP: Selegiline (Deprenyl$\left.{ }^{\oplus}\right)$; FAD: Flavin adenine dinucleotide cofactor; $\mathrm{H}_{2} \mathrm{O}_{2}$ : Hydrogen peroxide; HBSS: Hank's balanced salt solution; hMAO: Human MAO; hMAO: Recombinant human MAO; hMAO-BIs: Recombinant human MAO-B inhibitors; HRP: Horseradish peroxidase; IPS: Isopsoralen; MAO: Monoamine oxidase; NBI: Neobavaisoflavone; NE: Norepinephrine; PCS: Psoralea corylifolia L. seeds; PCSEE: PCS ethanolic extract; PD: Parkinson's disease; PS: Psoralen; PSD: Psoralidin; R; Retention factor; RIMA: Reversible inhibitors of MAO-A; RS: Relative selectivity; $R_{A}$ : RS in favor to inhibit $h M A O-A ; S_{B}:$ RS in favor to inhibit $h M A O-B ;$ Sl: $h M A O-B$ selectivity index; TLC: Thin-layer chromatography

\section{Acknowledgments}

We acknowledge the financial support to the first author (NOZ) by the National Board of Technical and Vocational Education, Misrata, Libya. We are grateful to OpenEye Scientific Software, Inc., Santa Fe, NM for their free Academic License.

\section{Funding}

This investigation was supported by NIH grants from NIMHD G12 MD007582 and P20 MD006738.

Availability of data and materials

Data are all contained within the manuscript. 


\section{Authors' contributions}

NOZ under the supervision of K. FAS, conceived and designed the study, performed in vitro, biochemical and chromatography studies, analyzed the data, interpreted the results, and wrote the manuscript. SVE performed the molecular docking studies. All authors read and approved the manuscript.

\section{Competing interests}

The authors declare that they have no competing interests.

\section{Consent for publication}

Not applicable.

\section{Ethics approval and consent to participate} Not applicable.

\section{Received: 23 April 2016 Accepted: 5 December 2016} Published online: 10 January 2017

\section{References}

1. Youdim MB, Bakhle YS. Monoamine oxidase: isoforms and inhibitors in Parkinson's disease and depressive illness. Br J Pharmacol. 2006;147 Suppl 1: S287-296

2. Naoi M, Maruyama W, Inaba-Hasegawa K. Type A and B monoamine oxidase in age-related neurodegenerative disorders: their distinct roles in neuronal death and survival. Curr Top Med Chem. 2012;12(20):2177-88.

3. O'Brien PJ, Siraki AG, Shangari N. Aldehyde sources, metabolism, molecular toxicity mechanisms, and possible effects on human health. Crit Rev Toxicol. 2005;35(7):609-62

4. Song MS, Matveychuk D, MacKenzie EM, Duchcherer M, Mousseau DD, Baker GB. An update on amine oxidase inhibitors: multifaceted drugs. Prog Neuropsychopharmacol Biol Psychiatry. 2013;44:118-24.

5. Mazzio E, Becker A, Soliman KF. Characterization of neurotransmitters and dopamine attenuation of inducible nitric oxide synthase in glioma cells. J Neuroimmunol. 2002;131(1-2):70-82.

6. Lotufo-Neto F, Trivedi M, Thase ME. Meta-analysis of the reversible inhibitors of monoamine oxidase type A moclobemide and brofaromine for the treatment of depression. Neuropsychopharmacology. 1999;20(3):226-47.

7. Patil PO, Bari SB, Firke SD, Deshmukh PK, Donda ST, Patil DA. A comprehensive review on synthesis and designing aspects of coumarin derivatives as monoamine oxidase inhibitors for depression and Alzheimer's disease. Bioorg Med Chem. 2013;21(9):2434-50.

8. Matos MJ, Vina D, Vazquez-Rodriguez S, Uriarte E, Santana L. Focusing on new monoamine oxidase inhibitors: differently substituted coumarins as an interesting scaffold. Curr Top Med Chem. 2012;12(20):2210-39.

9. Xiao ZP, Peng ZY, Peng MJ, Yan WB, Ouyang YZ, Zhu HL. Flavonoids health benefits and their molecular mechanism. Mini Rev Med Chem. 2011;11(2):169-77.

10. Huang M, Xie SS, Jiang N, Lan JS, Kong LY, Wang XB. Multifunctional coumarin derivatives: Monoamine oxidase B (MAO-B) inhibition, anti-betaamyloid (Abeta) aggregation and metal chelation properties against Alzheimer's disease. Bioorg Med Chem Lett. 2015;25(3):508-13.

11. Bang OY, Hong HS, Kim DH, Kim H, Boo JH, Huh K, Mook-Jung I. Neuroprotective effect of genistein against beta-amyloid-induced neurotoxicity. Neurobiol Dis. 2004;16(1):21-8.

12. Yanagihara $N$, Zhang $H$, Toyohira $Y$, Takahashi $K$, Ueno S, Tsutsui M, Takahashi K. New insights into the pharmacological potential of plant flavonoids in the catecholamine system. J Pharmacol Sci. 2014;124(2):123-8.

13. Khushboo PS, Jadhav VM, Kadam VJ, Sathe NS. Psoralea corylifolia Linn."Kushtanashini.". Pharmacogn Rev. 2010;4(7):69-76.

14. Chopra B, Dhingra AK, Dhar KL. Psoralea corylifolia L. (Buguchi) - folklore to modern evidence: a review. Fitoterapia. 2013;90:44-56.

15. Mazzio E, Deiab S, Park K, Soliman KF. High throughput screening to identify natural human monoamine oxidase B inhibitors. Phytother Res. 2013;27(6):818-28.

16. Zarmouh NO, Messeha SS, Elshami FM, Soliman KF. Natural Products Screening for the Identification of Selective Monoamine Oxidase-B Inhibitors. European J Med Plant. 2016;15(1):14802.

17. Zarmouh NO, Mazzio EA, Elshami FM, Messeha SS, Eyunni SVK, Soliman KFA Evaluation of the Inhibitory Effects of Bavachinin and Bavachin on Human Monoamine Oxidases A and B. Evid-Based Complement and Alternat Med. 2015;2015:14.
18. RafiqKhan M, Ranjini R. Preliminary phytochemical screening of seeds of Psoralea corylifolia. Int Res J Pharm. 2013;4(1):129-30.

19. Xiao G, Li G, Chen L, Zhang Z, Yin JJ, Wu T, Cheng Z, Wei X, Wang Z. Isolation of antioxidants from Psoralea corylifolia fruits using high-speed counter-current chromatography guided by thin layer chromatographyantioxidant autographic assay. J Chromatogr A. 2010;1217(34):5470-6.

20. Mao H, Wang H, Ma S, Xu Y, Zhang H, Wang Y, Niu Z, Fan G, Zhu Y, Gao $X M$. Bidirectional regulation of bakuchiol, an estrogenic-like compound, on catecholamine secretion. Toxicol Appl Pharmacol. 2014;274(1):180-9.

21. Backhouse CN, Delporte CL, Negrete RE, Erazo S, Zuniga A, Pinto A, Cassels BK. Active constituents isolated from Psoralea glandulosa L. with antiinflammatory and antipyretic activities. J Ethnopharmacol. 2001;78(1):27-31.

22. Zhao G, Zheng XW, Qin GW, Gai Y, Jiang ZH, Guo LH. In vitro dopaminergic neuroprotective and in vivo antiparkinsonian-like effects of Delta 3,2hydroxybakuchiol isolated from Psoralea corylifolia (L.). Cell Mol Life Sci. 2009;66(9):1617-29.

23. Zhao G, Li S, Qin GW, Fei J, Guo LH. Inhibitive effects of Fructus Psoraleae extract on dopamine transporter and noradrenaline transporter. J Ethnopharmacol. 2007;112(3):498-506.

24. Hsu YT, Wu CJ, Chen JM, Yang YC, Wang SY. The presence of three isoflavonoid compounds in Psoralea corylifolia. J Chromatogr Sci. 2001. 39(10):441-4.

25. Holt A, Sharman DF, Baker GB, Palcic MM. A continuous spectrophotometric assay for monoamine oxidase and related enzymes in tissue homogenates. Anal Biochem. 1997;244(2):384-92.

26. Valley MP, Zhou W, Hawkins EM, Shultz J, Cali JJ, Worzella T, Bernad L, Good T, Good D, Riss TL, et al. A bioluminescent assay for monoamine oxidase activity. Anal Biochem. 2006;359(2):238-46.

27. Legoabe $L$, Petzer A, Petzer JP. Selected C7-substituted chromone derivatives as monoamine oxidase inhibitors. Bioorg Chem. 2012;45:1-11.

28. Hawkins PC, Skillman AG, Warren GL, Ellingson BA, Stahl MT. Conformer generation with OMEGA: algorithm and validation using high-quality structures from the Protein Databank and Cambridge Structural Database. J Chem Inf Model. 2010;50(4):572-84

29. Chen Y, Kong LD, Xia X, Kung HF, Zhang L. Behavioral and biochemical studies of total furocoumarins from seeds of Psoralea corylifolia in the forced swimming test in mice. J Ethnopharmacol. 2005;96(3):451-9.

30. Kong LD, Tan RX, Woo AY, Cheng $\mathrm{CH}$. Inhibition of rat brain monoamine oxidase activities by psoralen and isopsoralen: implications for the treatment of affective disorders. Pharmacol Toxicol. 2001;88(2):75-80.

31. Carradori S, D'Ascenzio M, Chimenti P, Secci D, Bolasco A. Selective MAO-B inhibitors: a lesson from natural products. Mol Divers. 2014;18(1):219-43.

32. Vilar S, Ferino G, Quezada E, Santana L, Friedman C. Predicting monoamine oxidase inhibitory activity through ligand-based models. Curr Top Med Chem. 2012;12(20):2258-74.

33. Zarmouh NO, Messeha SS, Elshami FM, Soliman KF. Evaluation of the Isoflavone Genistein as Reversible Human Monoamine Oxidase-A and-B Inhibitor. Evid Based Complement Alternat Med. 2016;2016:1423052.

34. Wang J, He C, Wu WY, Chen F, Wu YY, Li WZ, Chen HQ, Yin YY. Biochanin A protects dopaminergic neurons against lipopolysaccharide-induced damage and oxidative stress in a rat model of Parkinson's disease. Pharmacol Biochem Behav. 2015;138:96-103.

35. Wu WY, Wu YY, Huang H, He C, Li WZ, Wang HL, Chen HQ, Yin YY. Biochanin A attenuates LPS-induced pro-inflammatory responses and inhibits the activation of the MAPK pathway in BV2 microglial cells. Int J Mo Med. 2015;35(2):391-8.

36. Tan JW, Tham CL, Israf DA, Lee SH, Kim MK. Neuroprotective effects of biochanin A against glutamate-induced cytotoxicity in PC12 cells via apoptosis inhibition. Neurochem Res. 2013;38(3):512-8.

37. Choi YH, Hong SS, Shin YS, Hwang BY, Park SY, Lee D. Phenolic compounds from Pueraria lobata protect PC12 cells against Abeta-induced toxicity. Arch Pharm Res. 2010;33(10):1651-4.

38. Occhiuto F, Zangla G, Samperi S, Palumbo DR, Pino A, De Pasquale R, Circosta $C$. The phytoestrogenic isoflavones from Trifolium pratense $L$. (Red Clover) protects human cortical neurons from glutamate toxicity. Phytomedicine. 2008;15(9):676-82.

39. Biradar SM, Joshi H, Chheda TK. Biochanin-A ameliorates behavioral and neurochemical derangements in cognitive deficit mice for the betterment of Alzheimer's disease. Hum Exp Toxicol. 2014;33(4):369-82. 
40. Verma A, Sharma S. Beneficial Effect of Protein Tyrosine Phosphatase Inhibitor and Phytoestrogen in Dyslipidemia-Induced Vascular Dementia in Ovariectomized Rats. J Stroke Cerebrovasc Dis. 2015;24(11):2434-46.

41. Barbosa RA, Nunes TL, Nunes TL, Paixao AO, Neto RB, Moura S, Albuquerque Junior RL, Candido EA, Padilha FF, Quintans-Junior LJ, et al. Hydroalcoholic extract of red propolis promotes functional recovery and axon repair after sciatic nerve injury in rats. Pharm Biol. 2016;54(6)993-1004.

42. Hu M, Krausz K, Chen J, Ge X, Li J, Gelboin HL, Gonzalez FJ. Identification of CYP1A2 as the main isoform for the phase I hydroxylated metabolism of genistein and a prodrug converting enzyme of methylated isoflavones. Drug Metab Dispos. 2003;31(7):924-31.

43. Tolleson WH, Doerge DR, Churchwell MI, Marques MM, Roberts DW. Metabolism of biochanin A and formononetin by human liver microsomes in vitro. J Agric Food Chem. 2002;50(17):4783-90.

44. Yoshihara S. A memoir of my researches on xenobiotic metabolism for 48 years-researches on Kanemi Yusho and endocrine disrupting chemicals. Yakugaku Zasshi. 2013;133(7):747-72.

45. Breikaa RM, Algandaby MM, El-Demerdash E, Abdel-Naim AB. Biochanin A protects against acute carbon tetrachloride-induced hepatotoxicity in rats. Biosci Biotechnol Biochem. 2013;77(5):909-16.

46. Hanski L, Genina N, Uvell H, Malinovskaja K, Gylfe A, Laaksonen T, Kolakovic R, Makila E, Salonen J, Hirvonen J, et al. Inhibitory activity of the isoflavone biochanin A on intracellular bacteria of genus Chlamydia and initial development of a buccal formulation. PLoS One. 2014:9(12):e115115.

47. Dreiseitel A, Korte G, Schreier P, Oehme A, Locher S, Domani M, Hajak G, Sand PG. Berry anthocyanins and their aglycons inhibit monoamine oxidases A and B. Pharmacol Res. 2009;59(5):306-11.

48. Chaurasiya ND, Ibrahim MA, Muhammad I, Walker LA, Tekwani BL. Monoamine Oxidase Inhibitory Constituents of Propolis: Kinetics and Mechanism of Inhibition of Recombinant Human MAO-A and MAO-B. Molecules (Basel, Switzerland). 2014;19(11):18936-52.

49. Herraiz T, Guillen $\mathrm{H}$. Inhibition of the bioactivation of the neurotoxin MPTP by antioxidants, redox agents, and monoamine oxidase inhibitors. Food Chem Toxicol. 2011;49(8):1773-81.

\section{Submit your next manuscript to BioMed Central and we will help you at every step:}

- We accept pre-submission inquiries

- Our selector tool helps you to find the most relevant journal

- We provide round the clock customer support

- Convenient online submission

- Thorough peer review

- Inclusion in PubMed and all major indexing services

- Maximum visibility for your research

Submit your manuscript at wuw biomedcentral.com/submit

) Biomed Central 